\title{
Lessons learned from developing online training for
} humanitarians

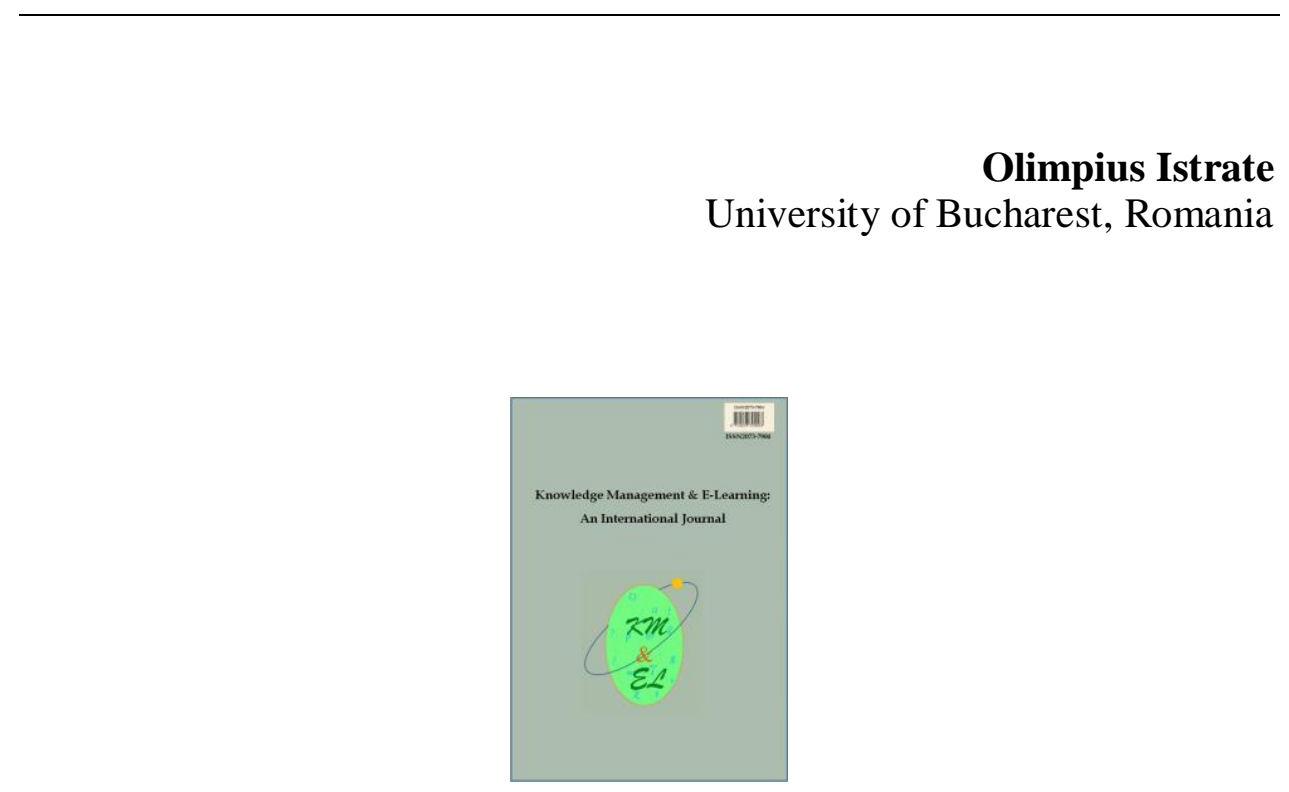

Knowledge Management \& E-Learning: An International Journal (KM\&EL) ISSN 2073-7904

Recommended citation:

Istrate, O. (2017). Lessons learned from developing online training for humanitarians. Knowledge Management \& E-Learning, 9(4), 419-432. 


\title{
Lessons learned from developing online training for humanitarians
}

\section{Olimpius Istrate*}

Faculty of Psychology and Education Sciences

University of Bucharest, Romania

E-mail: olimpius.istrate@g.unibuc.ro

*Corresponding author

\begin{abstract}
A comprehensive online learning programme with more than 200 courses was built by the International Federation of Red Cross and Red Crescent Societies between starting with 2009 and 2015, offering development opportunities to the Red Cross and Red Crescent (RCRC) volunteers and staff to broaden their understanding, to strengthen their organisations, and to be better prepared in providing humanitarian aid. While it is difficult to say to what extent factors such as training, job mentoring, and induction programmes contribute to job performance and to an organisation's efficiency, it is certain that staff and volunteers willing to undertake courses are more open to transformative and creative approaches, more prepared to tackle with new challenges, more likely to have a stock of knowledge and competencies broader than their own specialisation. Learning and "knowing to learn" are conditions for competitiveness and high performance. Over time, generally speaking, implementation of training as a priority personnel policy proved to have the most significant effects on productivity growth, therefore, efforts towards building a learning culture and delivering quality (online) learning are key for developing organisations, their staff, and the quality of services provided. An online training would make a significant difference in learners' behaviour if it follows several practical guidelines in development, accompanied by thorough checklists to ensure relevance, consistency, alignment and to assist training programmes' lifecycle.
\end{abstract}

Keywords: Open online learning; Training programmes; Volunteers training; Pedagogical principles; e-Learning

Biographical notes: Dr. Olimpius Istrate is Associate Professor in the Faculty of Psychology and Education Sciences, University of Bucharest, designing and teaching courses on Pedagogy, Computer-Assisted Instruction, Blended Learning, and Online Learning Environments. With over 15 years of experience in e-learning, pedagogy, education programmes evaluation, and teacher training, his professional path includes a research route at the Institute of Education Sciences, Bucharest, an education manager position for S-E Europe at Intel, and short-term assignments for various institutions such as Ministry of Education Romania, World Bank, the British Council, SIVECO Romania, Academia Online. Between 2013 and 2016, he was working in Geneva at the International Federation of Red Cross and Red Crescent Societies, as senior education officer, developing, managing and evaluating the online learning programme for volunteers and staff. 


\section{Introduction and context}

A popular Internet meme touches on the dilemma of investment in human resources - A Chief Financial Officer (CFO) poses the following question to the Chief Executive Officer (CEO): "What happens if we invest in developing our people and then they leave us?" The CEO answers, "What if we don't and they stay?" The situation is more complicated for the one undertaking the "CFO's challenge" above, since most of the times a directly proportional relationship between organizational culture and employees' productivity, or between investment in training and performance (Bartel 1991; ILO 2008, p.V) is difficult to capture - in other words, it is difficult to answer "What happens if we invest in developing our people and they stay?"

In practice, performance is indefinitely influenced as well by the extent to which learning culture is present, formally or informally endorsed by management and assumed by individuals, training is rich enough, relevant and on time, willingness to perform and to be better in professional and personal life is part of personality structure and nurtured (Halfond et al., 2015). Not least, understanding the meaning of personal and professional development for self and for the organisation, as well as what these require, are parts of the equation. In this light, learning opportunities are everywhere and for everybody, very diverse - formal, non-formal and informal - and growing with and within the career path, learning and work osmotically mixing together, interchangeable, a double helix of individual as well as organisational development (Giarini \& Malitza, 2003).

In a flash survey run in December 2015, Red Cross and Red Crescent (RCRC) volunteers and staff were asked what is their main reason for taking online courses on the Learning platform. As expected, almost half of the respondents (46.3\%, 106 volunteers and staff) answered that they want to improve their skills and knowledge in order to perform better in their work (see Fig. 1). More than a quarter felt that their presence in the learning environment was because they were requested to take courses.

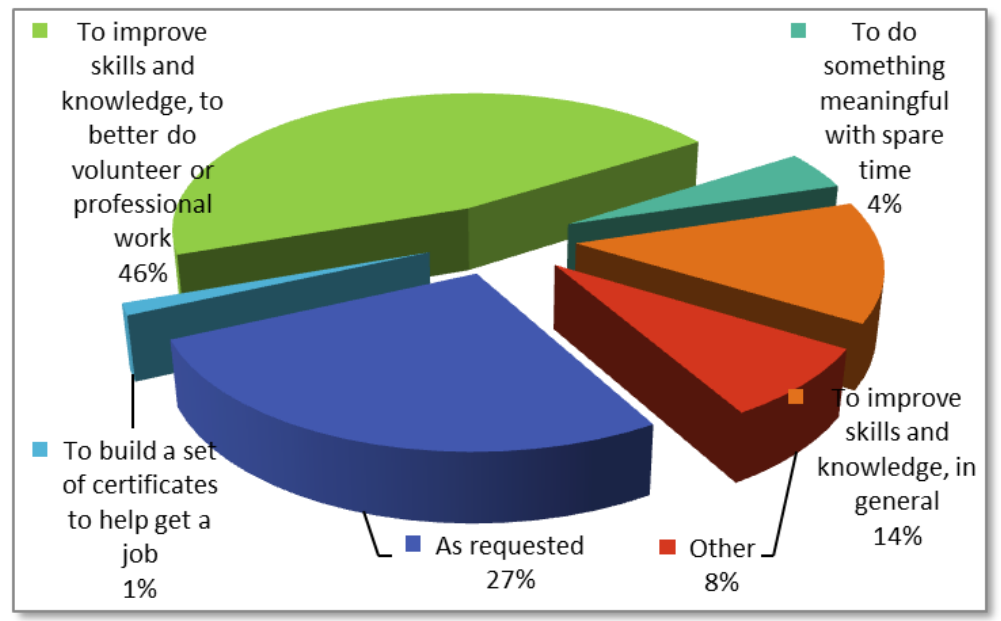

Fig. 1. Main reason for taking courses on RCRC platform $(\mathrm{N}=229)$

\section{An online training platform for humanitarians}

The growth of the RCRC Learning platform was consistent with the identified learning needs of RCRC staff and volunteers. A number of "essential" courses were developed in 
2009 at the beginning of the initiative and in the last two years, targeting specific RCRC skills and knowledge. In addition, general courses for personal development, in areas such as communication, management, leadership, are "borrowed" from third-party providers on a yearly basis, continuously renewed according to usage, feedback from learners, and learning needs of staff at International Federation of Red Cross and Red Crescent Societies (IFRC), staff in national societies, and RCRC volunteers. The number of courses offered on the RCRC learning platform is presented in Fig. 2.

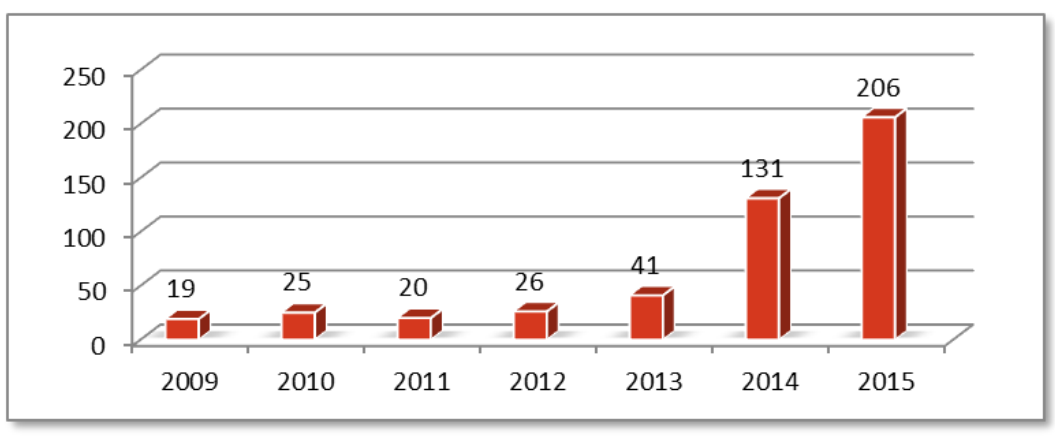

Fig. 2. Number of online courses available on the RCRC learning platform

Currently, the Learning platform has three main sections, splitting the course offering into categories to help learners to reach to the most relevant and to manage their learning paths:

- $\quad$ Training Packs 1: Red Cross and Red Crescent - with 60 courses distributed in subsections like Volunteering, National Society Development, Disaster Management, Health.

- Training Packs 2: Personal Development - 62 courses in 7 categories, related to interpersonal competencies such as teamwork, collaboration, communication, relationship building, influencing, resilience, adaptability, initiative.

- Training Packs 3: Professional Development - 25 courses distributed in 4 professional domains: Education and Training; HR; Logistics/Purchasing; PMER - planning, monitoring, evaluation, reporting.

There are almost 200,000 accounts on the RCRC Learning platform, out of which almost half are active users (accessing their accounts at least two times per year). The distribution by affiliation is restricted to the given categories available at registration on the platform:

- Volunteer RC/RC National Society (52\%)

- $\quad$ Staff RC/RC National Society (17\%)

- $\quad$ Staff IFRC (including former employees) and staff ICRC (8\%)

- $\quad$ Staff United Nations Organisation (1\%)

- $\quad$ Staff/Volunteer Non-for-Profit (3\%)

- $\quad$ Other affiliation (19\%).

Since 2009, there have been almost 500,000 registrations with the courses and close to 230,000 completions, with a very stable rate of completion of $45 \%$ over time. More details are presented in Fig. 3. As a research evaluation report states, "in total, the users of the platform have spent over 102 million minutes in courses - which is more than 
71 thousand days or 195 years in learning - figures that are showing the great interest raised and the scale of the programme" (Istrate, 2016). Over time, the platform turned out to be a veritable gateway to professional and personal development for a wide variety of people in the RCRC Movement (77\%), as well as for humanitarians in general (23\%).

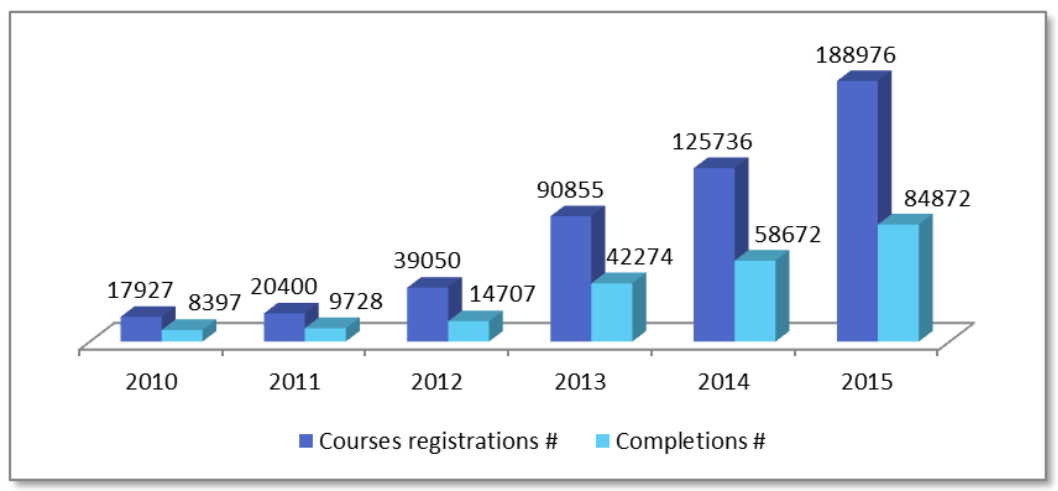

Fig. 3. Evolution of course registration and completion numbers

This paper capitalises upon the results of an intermediate review of online learning activities during 2010-2015, purposed to support the amelioration of the RCRC online learning programme. Currently, in May 2016, there are almost 100,000 active learners on the RCRC Learning platform, accounted for more than 10,000 registrations to courses and almost 5,000 completions every month.

\section{Developing online training}

The initiative places a high value and emphasis on quality in the development of online courses, having established a framework with several pillars to ensure the quality and relevancy of the trainings to its RCRC volunteers and staff (Velea, 2011; Istrate, 2016):

- The learning path's outcomes should be focused on being able to apply, rather than to remember information. In general, the learning objectives should vary by level, aiming the development of higher-order thinking skills as much as possible.

- Learner's capacity to transfer the models of action into other situations and in other domains should be developed.

- Learner should afterwards be able to act as a resource person and to further train others, in real-life situations; changes in attitude and behaviour should be targeted throughout the learning paths, by various means.

- Online learning materials should embed active learning methods to a satisfactory degree - depending on the topic, learning time, learning objectives; in this sense, priority should be given to (cognitive) interactivity, purposed for learning, rather than to "functional"-type navigation interactivity.

- Integrative approaches are preferable, treating the themes from multiple complementary or divergent perspectives and providing with a holistic approach to the subjects in focus.

- Interlinking courses and resources (of different nature, in different formats, from different platforms) helps building a significant and complete picture for the 
learners, a better understanding, and thus nurturing the feeling of belonging to global as well as to local communities.

- Different levels of difficulty, depth and specialisation should be taken into account and offered as alternatives, especially within the RCRC domain-specific listing of courses.

- A certain level (up to 30\%) of variance and divergence is beneficial considering the curricular components, starting with the visual design or technological solution and ending with the interpretation of the content (regardless if this is information, procedures, models of action, ways of thinking etc.) and with the pedagogical treatment of the content (deductive-inductive, analogic, algorithmical, transmissive-heuristic, interactive etc.).

Therefore, the RCRC online courses are developed against an in-house "checklist for new course development" (see Appendix III), comprising 30 criteria related to relevance, accessibility, pedagogical approach, content, and institutional value (Istrate \& Kestens, 2015). The courses are maintained following a specific standard operation procedure, which is covering the entire life-cycle of the "learning objects".

\section{Results and progress}

The introduction of the evaluation system in 2014 allows stakeholders to gauge important and interesting data regarding the online training offered by RCRC. Apart from the usual statistics on participation/interest (i.e., number of registrations, completions and time spent in training), feedback from learners is gathered in two periods of time. A satisfaction questionnaire is set up at course completion and an impact questionnaire is set up to be triggered 3 months after completion of each course (Haddock, 2015; Kirkpatrick, 1995). They are both optional, but built to gather a very fast feedback from learners -5 closed questions in each, with optional comment fields allowing focused input or suggestions (see Appendix I and Appendix II). In total, more than 72,000 responses were provided to the satisfaction questionnaire and more than 5,000 responses were provided to the impact questionnaire.

Learners on the IFRC Learning platform are very satisfied with the achievements and the learning experience. At completion, $82 \%$ rate the learning path undertaken as excellent $(54 \%)$ or above average $(28 \%)$. $44 \%$ agree and $48 \%$ strongly agree that they are better able to apply the respective skills and knowledge in their professional area. $95 \%$ would recommend the courses to a colleague (number of respondents $\mathrm{N}=72,110$ ).

Three months after completion, $86 \%$ of our learners consider what they learned helpful $(50 \%)$ or very helpful $(36 \%)$ for their professional work. They declared the courses enabled them to play a more supportive and constructive role in contributing to the organization where they work, to a great extent (50\% of the learners) or to a moderate extent $(34.5 \%)(\mathrm{N}=5,126)$.

Considering, for example, the first instance of feedback, we can now say that more than $90 \%$ of the learners - out of the total of 63,946 participating in the survey after completing at least a course from the 60 available in RCRC section. As shown in Fig. 4, they reported that become more able to apply the targeted specific skills and knowledge in their professional area after taking a RCRC online course. 


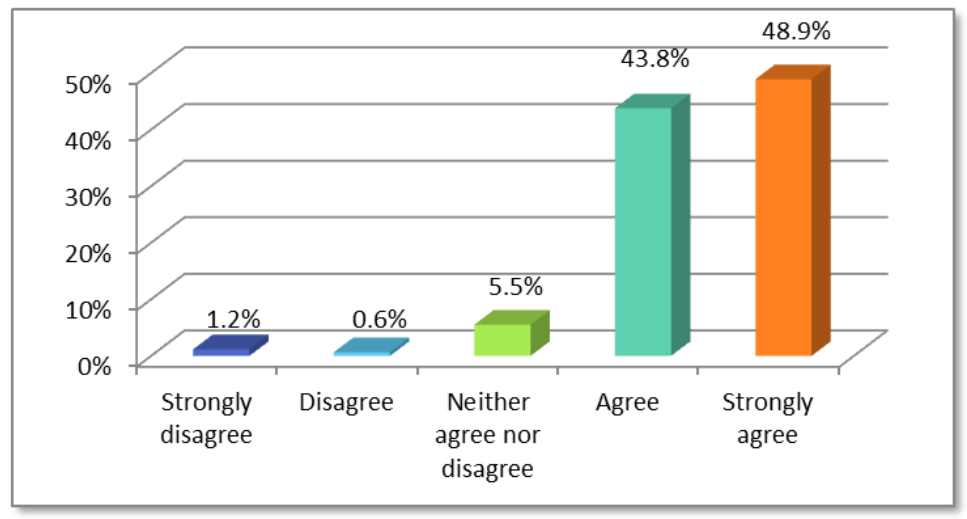

Fig. 4. Learners' perceptions of their readiness to apply specific skills and knowledge in their professional area $(\mathrm{N}=63,946)$

Three months after completion, the responses to the question "To what extent has this course enabled you to play a more supportive and constructive role in contributing to the organisation where you work?" were collected. The feedback, as shown in Fig. 5, helped the e-learning programme administrators to gauge the degree to which the courses in dedicated Red Cross and Red Crescent training area were relevant for their audience.

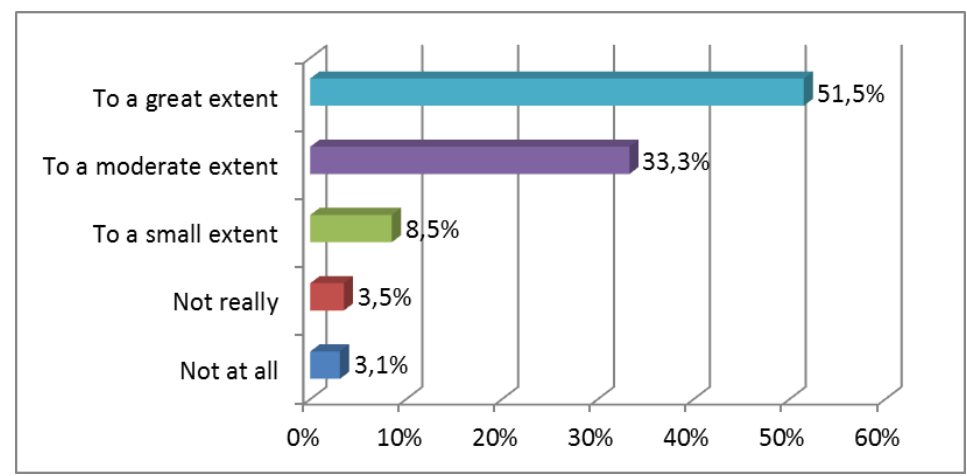

Fig. 5. Perceived relevance of a course to learners' professional role $(\mathrm{N}=3,962)$

The analysis of reaction, feedback and added value for participants can be focused on a specific course (with its language versions or per language), on a subsection or on a section, allowing comparisons and interpretations by theme or subtheme, by competency, by instructional method used, etc. (Ho et al., 2015). For example, the current data is showing that the added-value of the courses for personal development (62 courses available to date) is higher for Red Cross and Red Crescent volunteers than for staff.

This type of analysis, made possible through the implementation of the evaluation system, is supporting decision regarding correction of some parts of the programme and is providing the directions for future developments of online courses. Norm-based evaluation is currently used at IFRC to set quality thresholds and progress indicators, extremely useful when it comes to efficient administration of large course offerings and management of heterogeneous target group. Fig. 6 shows the feedback from the volunteers and staff in national societies in three months after they completed a course for personal development (62 courses were offered in total). The feedback was about the extent to which the course was helpful for them to take their role in the organisation. 


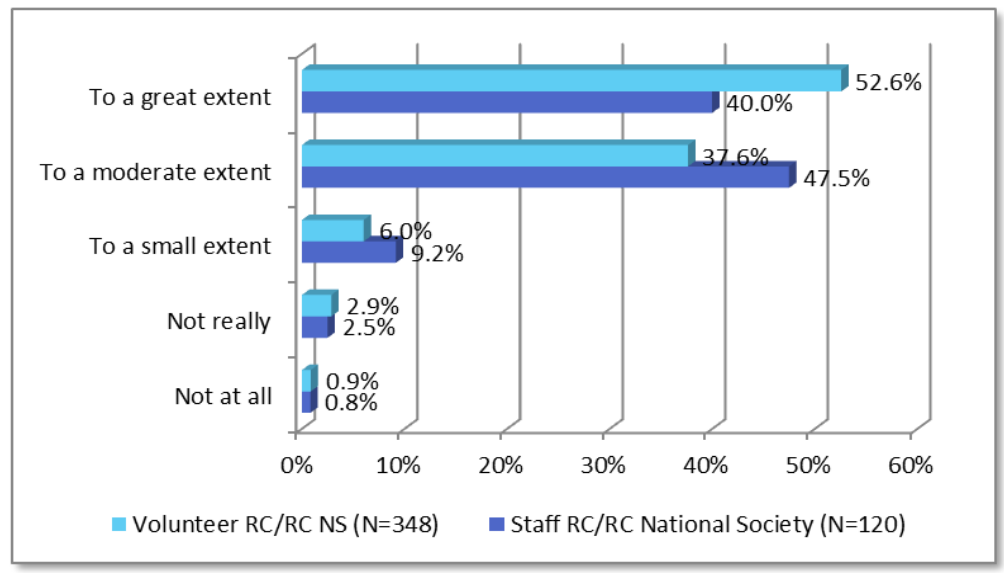

Fig. 6. Perceived relevance of a course to learners' role in their organisation

\section{Lessons learned}

High-quality learning is effectively possible in virtual environments even though the online course is self-paced, untutored, limited by constraints such as lack of possibilities of offering relevant incentives for continuous professional development paths, heterogeneous target group, with scarce access to Internet and lacking time, and so on. It is important that all parties involved are committing towards quality outcomes:

- Specialized pedagogical support is ensured from the inception stage;

- The subject matter experts understand the entire project as an education project (from designing the objectives to evaluating the effectiveness and impact) and take ownership, investing time and doing their best to embed up-to-date knowledge in the domain and to fully assist in transposing the content for learning purposes, seeking to place the learning into the "zone of proximal development" of the majority of learners in the target audience;

- Technical developers understand the specific pedagogical and content-related challenges of the given project.

Five components of the learning path are to be addressed when designing, developing and implementing online courses, starting with aims and objectives and ending with assessments, in iterative approaches equally involving the teams of instructional designers, subject matter experts and programmers (see Fig. 7).

An online training would make a significant difference in learners' behaviour if it follows several practical guidelines in development, such as:

- Attract the learner into a story, preferably using familiar situations or common dilemmas related to the content of the course. Participants learn best when they are personally involved in the learning scenario; personal engagement ensures mobilizing own resources towards understanding, transfer of learning achievement to personal or professional fields, capacity to analyse, see it from own perspective, further develop it and innovate. 
- Do not provide answers before letting the possibility for the learners to apply their own judgement. Knowledge, methods, solutions, values, adequate attitudes have to be discovered by their own means in order to make a difference in their behaviour. Constructing your own knowledge and/or know-how is the most important premise for long-term retention.

- Give adult learners freedom of choice and enough information to make choices. Nurture and trigger the intrinsic motivation. Commitment to learning is highest when they are free to set their own learning objectives and are able to actively pursue them within a given framework (Knowles, 1984). Set the correct expectations before enrolment in a course, by presenting the proposed learning objectives, the content, the learning time, the expected added-value of the training in concrete and immediate terms (Popham, 2005). Do not impose linear navigation throughout the entire course unless it is really necessary, enforced by the nature of content, objectives and overarching learning strategy established.

- Target higher-order thinking skills with your course. Problem solving and decision making, within almost any given domain, triggers specific methods asking the participants to raise and to solve complex issues (Yuan et al., 2016), to take important decisions - which in the end makes the learning path more interesting, captivating, challenging and therefore more likely to be completed.

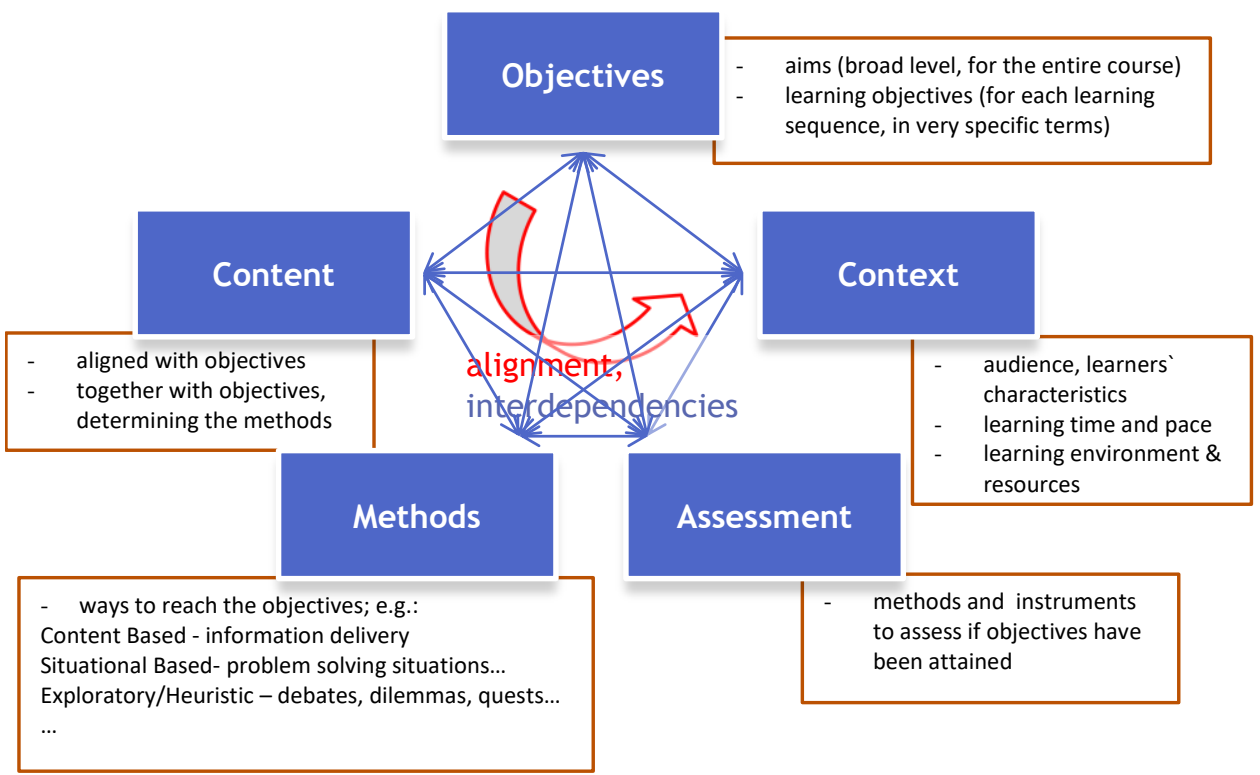

Fig. 7. The five components of the learning paths to be addressed in the design phase (in blue)

Regarding the content, criteria such as relevance and coherence should be taken into account. For example:

- Alignment: The course is in line with organisation's philosophy, principles, policies and approaches; authentic values and principles are implicit foundation for training. 
- Consistency and relevance: New courses are complementing the existing course offering; they are relevant for learning platform's main target groups; they are oriented to procedural knowledge and practical skills.

- Opportunity: The course is convergent/supporting organization's short- and medium-term strategy regarding training and staff development.

- Quality: The course is conformant to general quality assurance, including completeness, clarity, graphical clarity, and correct spelling and grammar as per the established quality standards.

An important lesson is supported by the pedagogical perspective: projects set up for developing the online courses do not need to be expensive in order to provide quality outputs and to add significant value to learners' acquisitions. The quality mainly resides in the instructional design.

Another good lesson to embed is regarding the overall programme design. Depending on the planned scale, target audience(s), resources available for development and quality assurance, some elements supplied by the training needs analysis, like competencies primarily targeted and themes to be covered, combined with expectations within determined timeframes, should reflect in an established and stable structure of the training offering, but also in procedures, mechanisms, tools set to ensure a sustainable online or blended training programme, able to show results and progress in the long-run.

Possible reformulations of the questions in the opening of this paper ("What happens if we invest in developing our people and then they leave us?" / "What happens if we invest in developing our people and they stay?") take into account a broader perspective, in which the exchange of human resources between organisations brings value for us as a large community of individuals and teams of individuals socially engaged and committed to progress beyond their own boundaries: "To better reach our objectives, how can we make our organisation an attractive place for high-performing and creative people?", or: "How could we create the right support mechanism to allow people to be as good as they can be?". It means keeping the right balance between people's motivation and the capacity of leaders to engage them--the individual preparedness, values and expectations and the organisational culture (Guy, Karen, \& Weinstein, 2005). Almost all the composing elements can be "imported" or "exported", equalising to some extent the institutional environments, but there is no doubt that there is a hidden label and a hierarchy of institutions when it comes to "where would you want to work", and usually this relies on organisational values and practices most of the times regardless (or at least counterbalancing) the financial benefits, such as trust, collaboration, support for personal development, freedom to choose and to innovate - pillars for intrinsic rewarding and sense of fulfilment and of progress (Caldwell, 2001).

In the humanitarian sector, organisations have the advantage of already committing to a meaningful purpose. Working in a humanitarian organisation is an opportunity to accomplish something of real value. Second in importance, training and coaching are a significant part of embedding intrinsic motivation and engagement into the organisation's culture. The capstone question (rhetorical, to a certain extent) could be phrased as: Can humanitarianism thrive without professionalism? (Walker, 2004) - as a piece of argumentation inevitably leading nowadays to the need of continuous investment in training the human resources providing critical, life-saving work in a humanitarian response, by making available appropriate learning opportunities, and moreover establishing a sustainable organisational culture based on continuous professional development. "Profitability" and "productivity" are still counted, their correlation with 
investment in human resources can still be measured, but the meanings are slightly different, as the performance is being beneficial to all--our global village.

\section{Acknowledgements}

The author would thank the International Federation of Red Cross and Red Crescent Societies, Geneva - the Learning \& Research Department and the HR Department - for initiating and developing the online learning programme and the evaluation research whose partial results are presented in this article.

\section{References}

Bartel, A. P. (1991). Productivity gains from the implementation of employee training programs. Industrial Relations, 33(4), 411-425.

Caldwell, R. (2001). Champions, adapters, consultants and synergists: The new change agents in HRM. Human Resource Management Journal, 11(3), 39-52.

Giarini, O., \& Malitza, M. (2003). The double helix of learning and work. Bucharest: UNESCO-CEPES. Retrieved from unesdoc.unesco.org/images/0013/001307/130713eb.pdf

Guy, G. R., Karen, V. B., \& Weinstein, C. (2005). Effecting change in business enterprises: Current trends in change management. New York, NY: The Conference Board. Retrieved from corprenewal.co.za/pdf/effecting\%20change\%20in\%20business\%20enterprises.pdf

Haddock, P. (2015). Monitoring and evaluating training: Challenges, opportunities and recommendations (Praxis Paper 30). Oxford: INTRAC. Retrieved from www.intrac.org/resources/praxis-paper-30-monitoring-evaluating-training-challengesopportunities-recommendations/

Halfond, J. A., Casiello, A., Cillay, D., Coleman, N., Cook, V., LaBrie, J., Niemiec, M., \& Salley, W. (2015). UPCEA Hallmarks of excellence in online leadership. Washington, DC: UPCEA. Retrieved from http://www.upcea.edu/hallmarks

Ho, A. D., Chuang, I., Reich, J., Coleman, C. A., Whitehill, J., Northcutt, C. G., ... Petersen, R. (2015). HarvardX and MITx: Two years of open online courses fall 2012- summer 2014. SSRN. doi: 10.2139/ssrn.2586847

International Labour Office (ILO). (2008). Skills for improved productivity, employment growth and development. Paper presented at International Labour Conference (97th Session). Geneva, Switzerland. Retrieved from www.ilo.org/wcmsp5/groups/public/@ed_norm/@relconf/documents/meetingdocume nt/wcms_092054.pdf

Istrate, O. (2016). A journey to diversified and personalised learning: The Red Cross and Red Crescent online learning platform - Evaluation results. In Proceedings of the 11th International Conference on Virtual Learning (ICVL). Retrieved from http://c3.icvl.eu/papers2016/icvl/documente/pdf/section3/section3 paper35.pdf

Istrate, O., \& Kestens, A. (2015). Developing and monitoring a MOOC: The IFRC experience. In Proceedings of the 11th International Scientific Conference eLearning and Software for Education (vol. 2, pp. 576-583). doi: 10.12753/2066-026X-15-179

Kirkpatrick, D. L. (1959). The Kirkpatrick Model. Kirkpatrick Partners. Retrieved from kirkpatrickpartners.com/OurPhilosophy/TheKirkpatrickModel

Knowles, M. (1984). The adult learner: A neglected species (3rd ed.). Houston, TX: Gulf Publishing.

Popham, W. J. (2005). Students' attitudes count. Educational Leadership, 62(5), 84-85. 
Velea, S. (2011). ICT in education: Responsible use or a fashionable practice - The impact of eTwinning action on the education process. In Proceedings of the 6th International Conference on Virtual Learning (ICVL) (pp. 141-144).

Walker, P. (2004). What does it mean to be a professional humanitarian? The Journal of Humanitarian Assistance. Retrieved from https://sites.tufts.edu/jha/archives/73

Yuan, B., Wang, M., Kushniruk, A. W., \& Peng, J. (2016). Design of a computer-based learning environment to support diagnostic problem solving towards expertise development. Knowledge Management \& E-Learning, 8(4), 540-549. 


\section{Appendix I.}

\section{The Questionnaire for Satisfaction Evaluation (Level 1), English Version}

What are your thoughts regarding this course? ...

1. In general, how would you rate your experience of the course?

1-Poor/2-Below average /3-Average /4-Above average /5-Excellent

2. Do you have any comments or concerns regarding the content of this course?

Yes / No

If your answer is YES, please specify:

3. Did you have any technical problems accessing or following the course?

Yes / No

If you answered YES, please specify, in short:

4. Do you feel you are now better able to apply these specific skills and knowledge in your professional area?

1- Strongly disagree / 2- Disagree / 3- Neither agree nor disagree / 4- Agree / 5- Strongly agree

5. Would you recommend this course to your colleagues?

Yes / No

\section{Appendix II.}

\section{The Questionnaire for Impact Evaluation (Level 3), English Version}

Three months after the completion of the course, we would be very interested to know if it has been helping you with your personal or professional development.

1. Overall, do you feel that what you learned in this course was helpful for your professional work in this area?

1- Not at all helpful / 2-Slightly helpful /3- Moderately Helpful / 4-Very helpful / 5- Extremely helpful

Comments (optional):

2. How much would you say you remember of the course content?

1- Nothing / 2- A small amount / 3- A reasonable amount / 4- Almost everything / 5- Everything Comments (optional):

3. Since you took the course, how often have you been able to APPLY the specific skills and/or knowledge that you learned?

1- Not at all / 2- Occasionally (monthly) / 3- Often (weekly) / 4-Frequently (several times a week) / 5- All the time (everyday)

Comments (optional):

4. To what extent has this course enabled you to play a more supportive and constructive role in contributing to the organisation where you work?

1- Not at all / 2- Not really / 3- To a small extent / 4- To a moderate extent / 5- To a great extent

Comments (optional):

5. If you have any other comment on any aspect of the course you took, or any other aspect of the IFRC's Learning Platform, please mention it here: 


\section{Appendix III.}

Checklists for development of new courses at IFRC

Part A: Validation criteria

Checklist-based validation to be performed in three rounds: on the first version of the storyboard, when half of the course is in e-learning format, when the course is ready to be launched.

\begin{tabular}{|c|c|c|c|c|}
\hline & $\begin{array}{l}\text { Unaccept } \\
\text { able }\end{array}$ & Sufficient & $\begin{array}{l}\text { Good/To } \\
\text { a large } \\
\text { extent }\end{array}$ & Comment \\
\hline \multicolumn{5}{|l|}{ Relevance } \\
\hline $\begin{array}{l}\text { The curriculum is covering a significant or important } \\
\text { part of the knowledge and/or skills necessary to } \\
\text { professionals/ volunteers in the target group. } \\
\text { (contribution to development) }\end{array}$ & $\square$ & $\square$ & $\square$ & \\
\hline $\begin{array}{l}\text { The curriculum provides information and landmarks } \\
\text { adequated to the target group' needs. (value against } \\
\text { expectations/ needs) }\end{array}$ & $\square$ & $\square$ & $\square$ & \\
\hline $\begin{array}{l}\text { The curriculum includes practical info, realistic } \\
\text { problems, goal-based scenarios and useful examples } \\
\text { designed to sustain improvements in behaviour. } \\
\text { (anchored instruction; sustains authentic learning) }\end{array}$ & $\square$ & $\square$ & $\square$ & \\
\hline $\begin{array}{l}\text { The curriculum can significantly contribute to } \\
\text { improving the activity of professionals/ volunteers in the } \\
\text { target group. (foreseen impact) }\end{array}$ & $\square$ & $\square$ & $\square$ & \\
\hline \multicolumn{5}{|l|}{ Accessibility } \\
\hline Content is easy to follow and understand. & $\square$ & $\square$ & $\square$ & \\
\hline $\begin{array}{l}\text { Vocabulary is clear, coherent and adequated to the level } \\
\text { of target audience. }\end{array}$ & $\square$ & $\square$ & $\square$ & \\
\hline $\begin{array}{l}\text { Visual design principles are effectively used - text, } \\
\text { images, layout, colours, (navigation) icons. }\end{array}$ & $\square$ & $\square$ & $\square$ & \\
\hline $\begin{array}{l}\text { Navigation throughout the course is smooth and } \\
\text { intuitive. }\end{array}$ & $\square$ & $\square$ & $\square$ & \\
\hline $\begin{array}{l}\text { Access of persons with disabilities is considered \& } \\
\text { possible. }\end{array}$ & $\square$ & $\square$ & $\square$ & \\
\hline The course can be run on mobile. & $\square$ & $\square$ & $\square$ & \\
\hline \multicolumn{5}{|l|}{ Pedagogical approach } \\
\hline $\begin{array}{l}\text { The curriculum offers the necessary elements for } \\
\text { learning progress in the given area (purposefulness } \\
\text { towards knowledge acquisition and/or skills } \\
\text { development) }\end{array}$ & $\square$ & $\square$ & $\square$ & \\
\hline $\begin{array}{l}\text { The aims are correctly formulated, covering overall } \\
\text { learning acquisition. (coherence, alignment) }\end{array}$ & $\square$ & $\square$ & $\square$ & \\
\hline $\begin{array}{l}\text { Learning objectives are correctly formulated (ABCD- } \\
\text { Mager/SMART) }\end{array}$ & $\square$ & $\square$ & $\square$ & \\
\hline $\begin{array}{l}\text { Learning objectives are covering/ supporting the entire } \\
\text { sphere of the course aims. (coherence) }\end{array}$ & $\square$ & $\square$ & $\square$ & \\
\hline $\begin{array}{l}\text { Learning objectives are set on several levels of thinking } \\
\text { skills. (authentic/ deep learning) }\end{array}$ & $\square$ & $\square$ & $\square$ & \\
\hline $\begin{array}{l}\text { The outline is complete and sufficient for covering the } \\
\text { course aims. (completeness of themes inventory) }\end{array}$ & $\square$ & $\square$ & $\square$ & \\
\hline $\begin{array}{l}\text { The content is completely covering the learning } \\
\text { objectives set. (alignment) }\end{array}$ & $\square$ & $\square$ & $\square$ & \\
\hline $\begin{array}{l}\text { The content is a result of transposition of text/ } \\
\text { information from the reference resources (source }\end{array}$ & $\square$ & $\square$ & $\square$ & \\
\hline
\end{tabular}




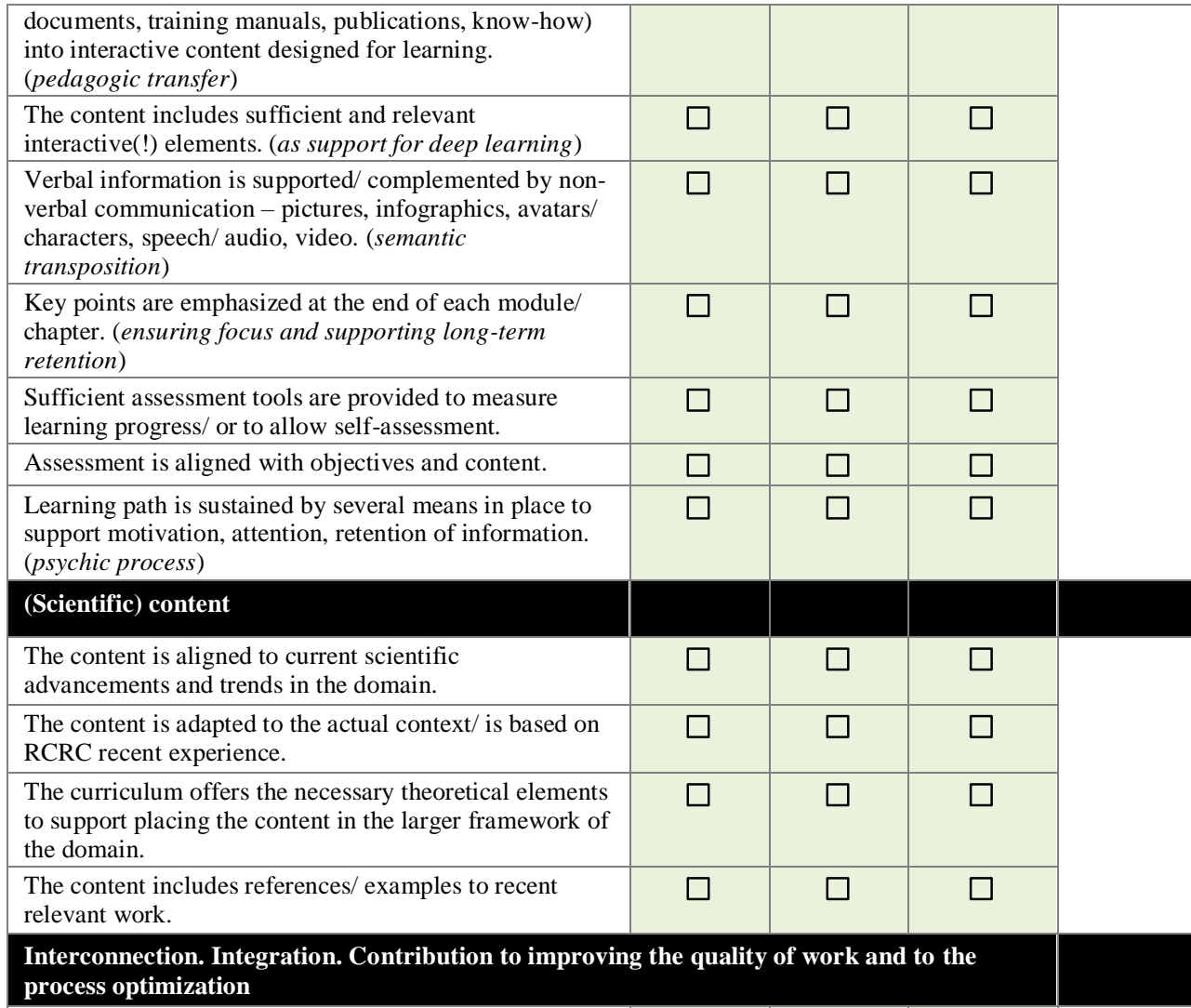
process optimization

The course is in line with the Fundamental Principles of RCRC Movement.

The course is aligned with the IFRC Competency Framework and/ or with the Humanitarian Values.

The curriculum allows/ includes liaisons with other professional development courses at RCRC/IFRC.

The themes and the approach could facilitate a new vision and creativity in participants' current professional tasks and/ or personal life. (Innovation)

Part B: curriculum alignment and accuracy

\begin{tabular}{|l|l|c|c|c|c|}
\hline & $\begin{array}{l}\text { Learning objective and its rank on } \\
\text { Bloom-Anderson taxonomy }\end{array}$ & $\begin{array}{c}\text { Theory/ } \\
\text { Info }\end{array}$ & Examples & Exercises & Assessment \\
\hline 1 & $\begin{array}{l}\ldots \\
\text { Notes: }\end{array}$ & $\square$ & $\square$ & $\square$ \\
\hline 2 & $\ldots$ & $\square$ & $\square$ & $\square$ & $\square$ \\
\hline 3 & $\ldots$ & $\ldots$ & $\ldots$ & $\ldots$ & \\
\hline
\end{tabular}

